\title{
Japan Scar Workshop (JSW) Scar Scale (JSS) for Assessing Keloids and Hypertrophic Scars
}

Rei Ogawa

\section{Contents}

15.1 Background - 134

15.2 JSW Scar Scale (JSS) 2015 - 134

15.3 Classification Table - 134

15.4 Evaluation Table - 134

15.5 Clinical Suitability and Usefulness of the JSS - 136

15.6 Conclusion - 136

References - 140 


\subsection{Background}

The Vancouver scar scale [1], the Manchester scar scale [2], and the Patient and Observer Scar Assessment Scale (POSAS) [3] are all very well-known scar evaluation methods. These tools are based on a number of scar variables, including color, height, and pliability. However, since all were mainly developed to evaluate burn scars, they are difficult to use in clinical practice for keloids and hypertrophic scars. This is because these pathological scars require both differential diagnosis and a way to evaluate their response to therapy. Since the Japan Scar Workshop (JSW) was established in 2006, it has sought to develop a scar assessment scale that meets these clinical needs. The first version of this scar assessment tool was named the JSW scar scale (JSS), and it was reported in 2011 [4]. In 2015, the revised second version was reported (- Table 15.1 and - Figs. 15.1, 15.2, 15.3, 15.4, 15.5, 15.6, and 15.7) [5]. This chapter introduces the JSS and discusses its clinical importance and usefulness in scar research.

\subsection{JSW Scar Scale (JSS) 2015}

The JSS consists of two tables. One is a scar classification table that is used to determine whether the scar is a normal mature scar, a hypertrophic scar, or a keloid. This grading system helps the user to select the most appropriate treatment method for the scar. The other table in the JSS is an evaluation table that is used to judge the response to treatment and for follow-up. Both tables contain sample images of each subjective keloid/ hypertrophic scar item that allow the user to evaluate each item without hesitation (- Figs. 15.1, 15.2, 15.3, $15.4,15.5,15.6$, and 15.7). Japanese guidelines for the prevention and treatment of keloids and hypertrophic scars [6] include JSS 2015.

\subsection{Classification Table}

The classification table consists of two parts: risk factors and the present symptoms. The risk factors consists of six items, each of which has 2-3 categories: (1) human race (African, Other, Caucasian), (2) whether there is a familial tendency (Clearly exists, Does not clearly exist), (3) the number of scars (Multiple, Solitary), (4) the body region the scar is on (Anterior chest/scapular-shoulder/suprapubic, Other), (5) the age at onset $(0-30,31-60, \geq 60$ years), and (6) the cause(s) (Unknown/minute, Specific type of wounding such as surgery). The present symptoms also consist of six items, each of which has 2-3 categories: (7) scar size $\left(>20 \mathrm{~cm}^{2},<20 \mathrm{~cm}^{2}\right),(8)$ whether there is vertical growth (Clearly exists, Does not clearly exist), (9) whether there is horizontal growth (Clearly exists, Does not clearly exist), (10) the shape of the scar (Characteristic shape, Others), (11) whether there is erythema around the scar (Clearly exists, Does not clearly exist), and (12) whether there are subjective symptoms (Always exist, Intermittent, None). Thus, the classification table consists of 12 items in total. The categories in each item are weighted: for example, in Human race, African, Caucasian, and Other races are weighted 2, 0 , and 1 points, respectively. The minimum and maximum number of points in the classification table are 0 and 25 , respectively. If the classification score is $0-5$, the scar is deemed to have mature scar characteristics. If the score is $6-15$ or $16-25$, the scar is deemed to be a hypertrophic scar and a keloid, respectively.

This grading system is thus used to differentially diagnose keloid and hypertrophic scars. It is necessary to have this system because there are many cases in which the scar bears the growth and histological features of both hypertrophic scars and keloids; as a result, it can be difficult to differentially diagnose these scars in real clinical practice. This reality is not mirrored by the current dogma about pathological scars. Thus, many classical textbooks consider keloids and hypertrophic scars to be completely different types of scar. Clinicians define hypertrophic scars as scars that do not grow beyond the boundaries of the original wound, whereas keloids are defined as scars that spread into the surrounding normal skin. Pathologists have their own definitions; they make a histological distinction between keloids and hypertrophic scars on the basis of thick eosinophilic (hyalinizing) collagen bundles called "keloidal collagen": these are present in the former scar type but rarer in the latter. However, we have observed many cases that do not fit these dichotomic definitions. For example, scars with hypertrophic growth characteristics can bear considerable keloidal collagen. Indeed, it is possible that hypertrophic scars and keloids are manifestations of the same fibroproliferative skin disorder and just differ in the intensity and duration of inflammation. These inflammatory features may be shaped by genetic, systemic, and local risk factors [7].

\subsection{Evaluation Table}

The evaluation table consists of six items: (1) Induration, (2) Elevation, (3) Redness of the scar, (4) Erythema around the scar, (5) Spontaneous and pressing pain, and (6) Itch. Each item has four intensity categories, namely, None, Weak, Mild, and Strong. These categories are weighted $0,1,2$, and 3 , respectively. There are sample 


\section{- Table 15.1 JSW Scar Scale (JSS) 2015 (Classification and Evaluation of Keloids and Hypertrophic Scars)}

Classification (for grading and selection of appropriate treatment methods)

\section{Risk factors}

1. Human race

2. Familial tendency

3. Number

4. Region

5. Age at onset

6. Causes

Present symptoms

\begin{tabular}{l|l|}
\hline 7. Size $\left(\mathrm{cm}^{2}\right)$ & Over $20 \mathrm{~cm}^{2}$ \\
\hline $\begin{array}{l}\text { 8. Vertical growth } \\
\text { (elevation) (- Fig. 15.1) }\end{array}$ & Clearly exists \\
\hline $\begin{array}{l}\text { 9. Horizontal growth } \\
\text { Not clearly }\end{array}$ \\
\hline
\end{tabular}

(• Fig. 15.2)

\section{Not clearly}

10. Shape (• Fig. 15.3)

Characteristic shape

Others

11. Erythema around scars (• Fig. 15.4)

\section{Subjective symptoms}

\section{Total 0-25}

\section{Remarks}

$0-5$

$$
\text { 6-1 }
$$

$16-25$

Others

Caucasians

Not clearly

Anterior chest, scapular-shoulder, suprapubic

Others

0-30 y/o

$60 \mathrm{y} / \mathrm{o}$

Specific wound type such as surgery

Clearly present

Not present

Always exist

Intermittent

None low risk)

Character like hypertrophic scars (intractability, middle risk)
Evaluation (for judging treatment results and for following-up)

\section{Induration}

0 : None

1: Weak

2: Mild

3: Strong

1

2. Elevation (• Fig. 15.5)

0 : None

1: Weak

2: Mild

3: Strong

3. Redness of scars (• Fig. 15.6)

0 : None

1: Weak

2: Mild

3: Strong

2

4. Erythema around scars (• Fig. 15.7)

\begin{tabular}{l|l|l|l}
$0:$ None & 1: Weak & 2: Mild & 3: Strong
\end{tabular}

$31-60 \mathrm{y} / \mathrm{o}$

5. Spontaneous and pressing pain

0 : None

1: Weak 2: Mild 3: Strong

0
6. Itch

0 : None

1: Weak

2: Mild

3: Strong

0

2 Total $0-18$

0 Remarks

3 Weak: symptoms exist in less than $1 / 3$ of the area, or are intermittently

0 Strong: symptoms exist in the entire region, or are continuous

3 Mild: between weak and strong

0

2

0

2

Character like matured scars (intractability,

Character like keloids (intractability, high risk) 

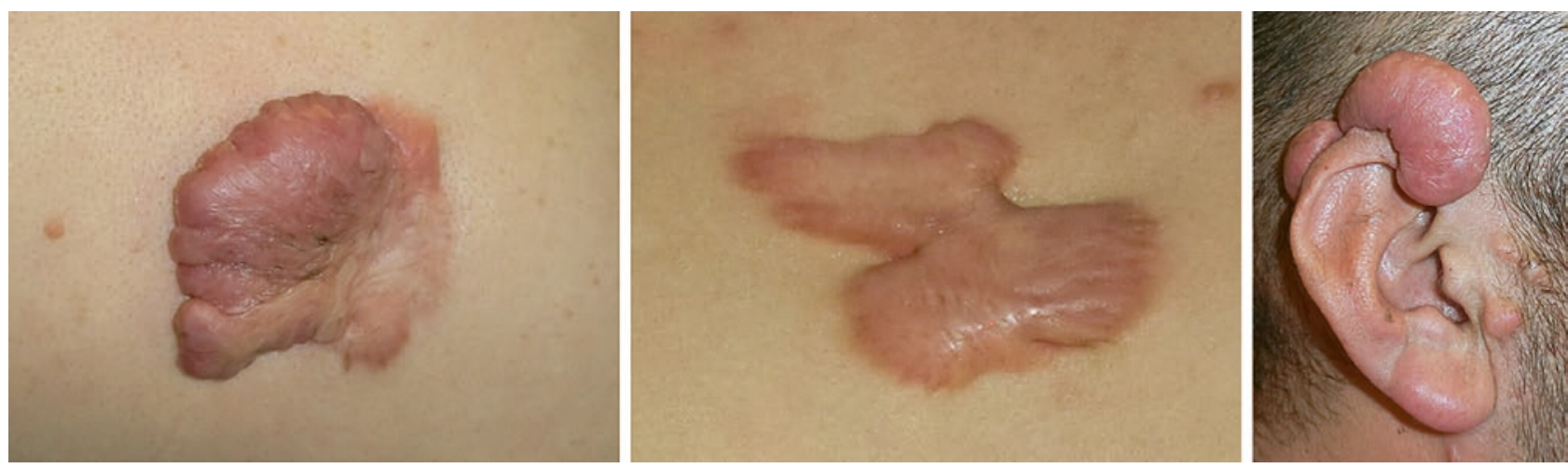

Clearly exists
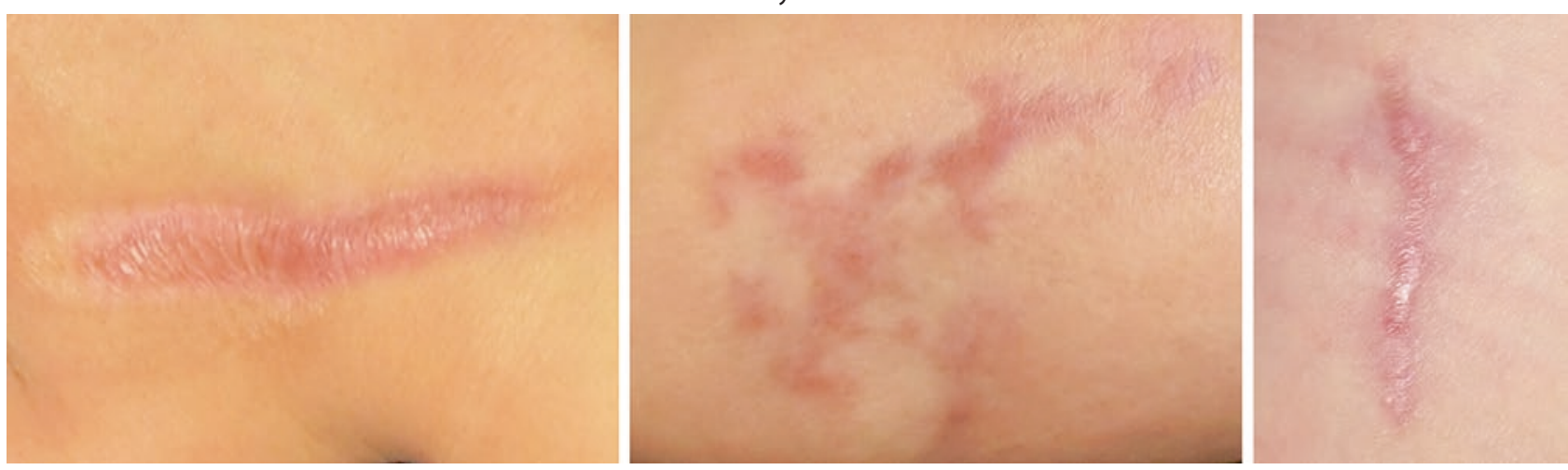

Not clear

- Fig. $\mathbf{1 5 . 1}$ Vertical growth (elevation)

images of each category in each item that helps the user judge the items. The minimum and maximum total points in the evaluation table are thus 0 and 18, respectively. When the symptoms improve, the total score decreases. also used in a study in Taiwan [9]. However, in our experience, different regions of the world vary in terms of the severity of keloids and hypertrophic scars: in particular, keloids appear to be singularly severe in Africa and East-South Asia, while being rare in western countries. Therefore, in the future, the JSS2015 should be modified to cover other regions of the world.

\subsection{Conclusion}

The Japan Scar Workshop (JSW) developed the JSW scar scale (JSS) to evaluate keloids and hypertrophic scars. The JSS consists of two tables; one is a scar classification table that is used to determine whether the scar is a normal mature scar, a hypertrophic scar, or a keloid, and the other table is an evaluation table that is used to judge the response to treatment and for follow-up. The JSS became a standard classification and evaluation tool for keloid and hypertrophic scars in Japan. In the future, the JSS5 should be modified to cover other regions of the world. 

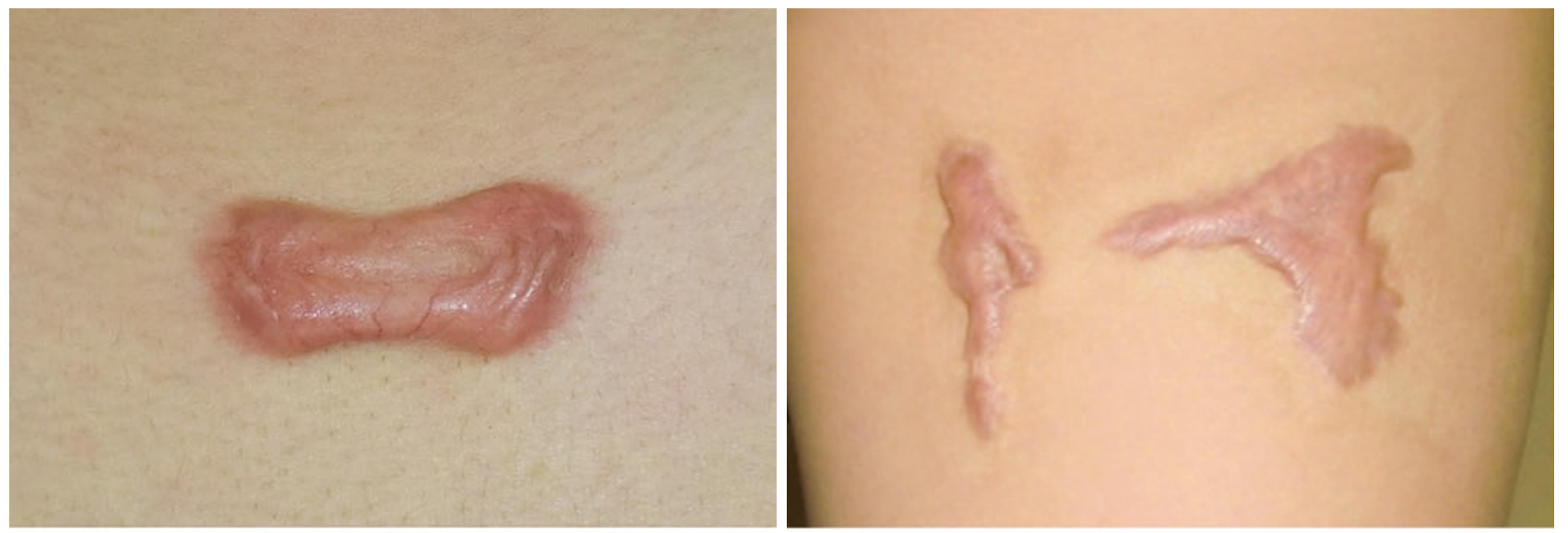

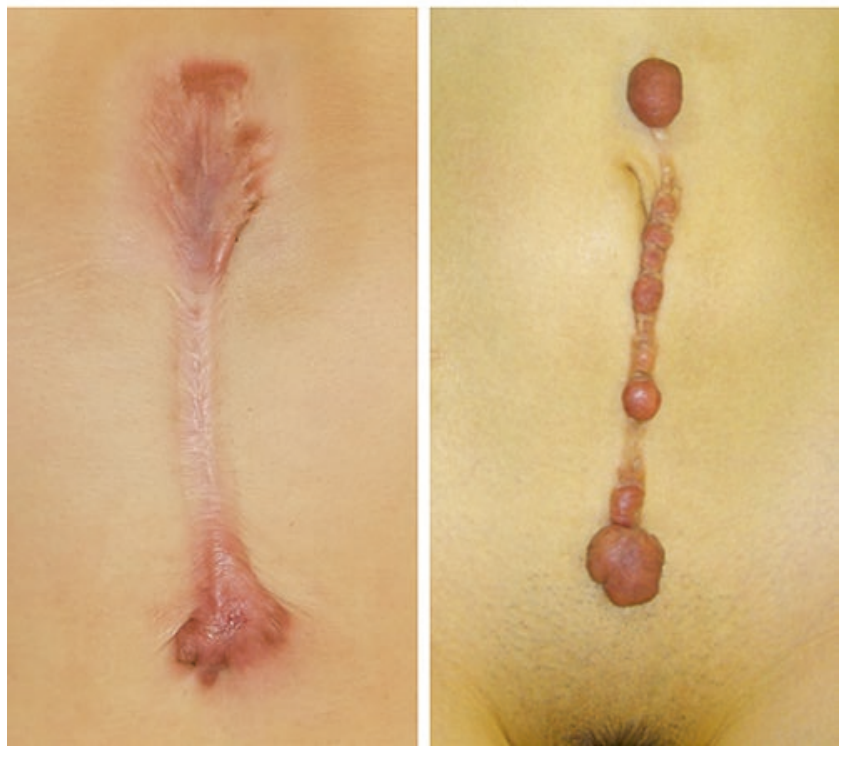

Clearly exists

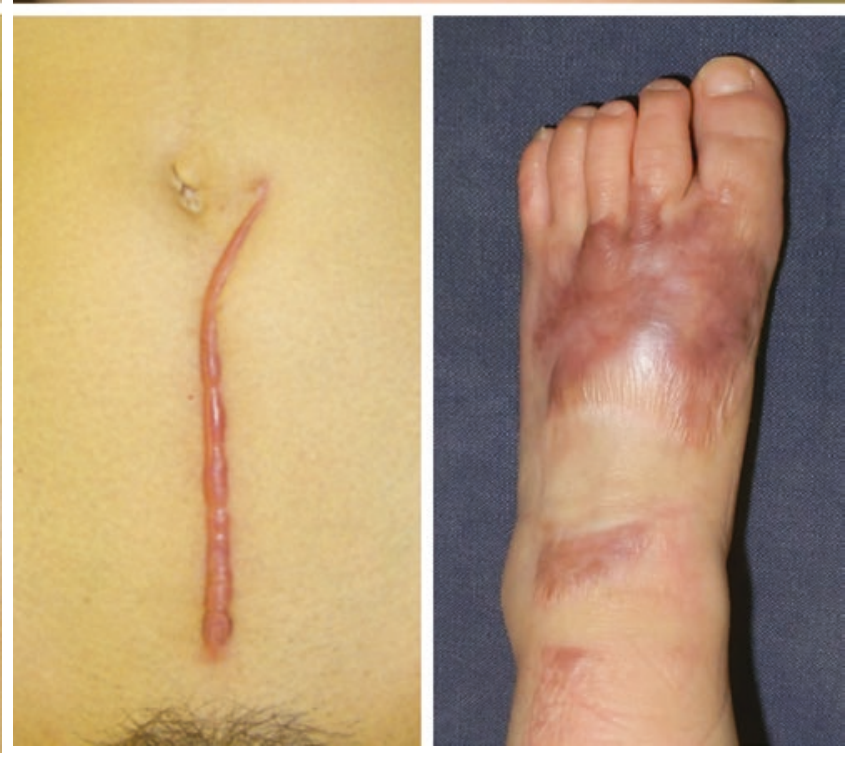

Not clear

- Fig. 15.2 Horizontal growth
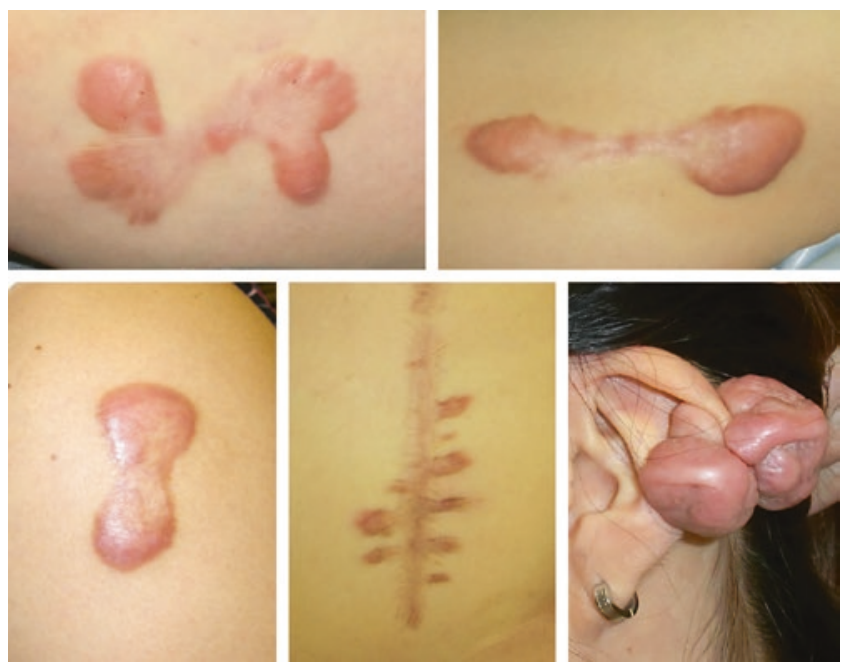

Characteristic shape

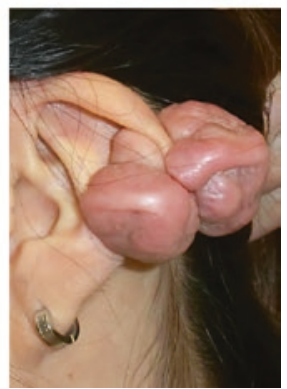

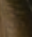
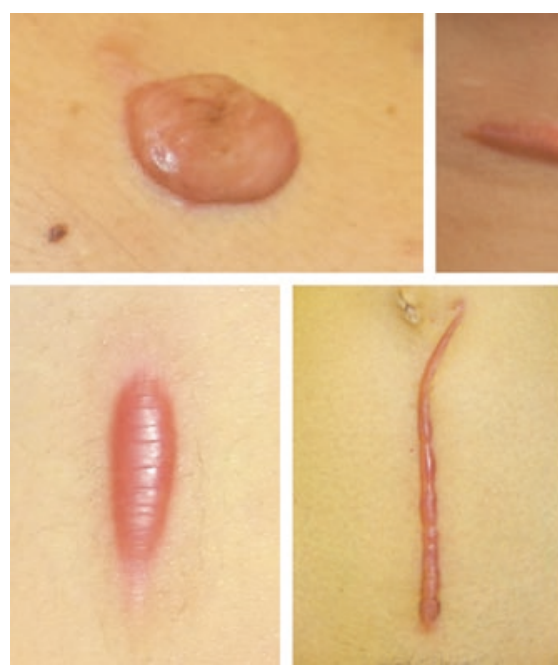

Others

- Fig. 15.3 Shape 
- Fig. 15.4 Erythema around scars
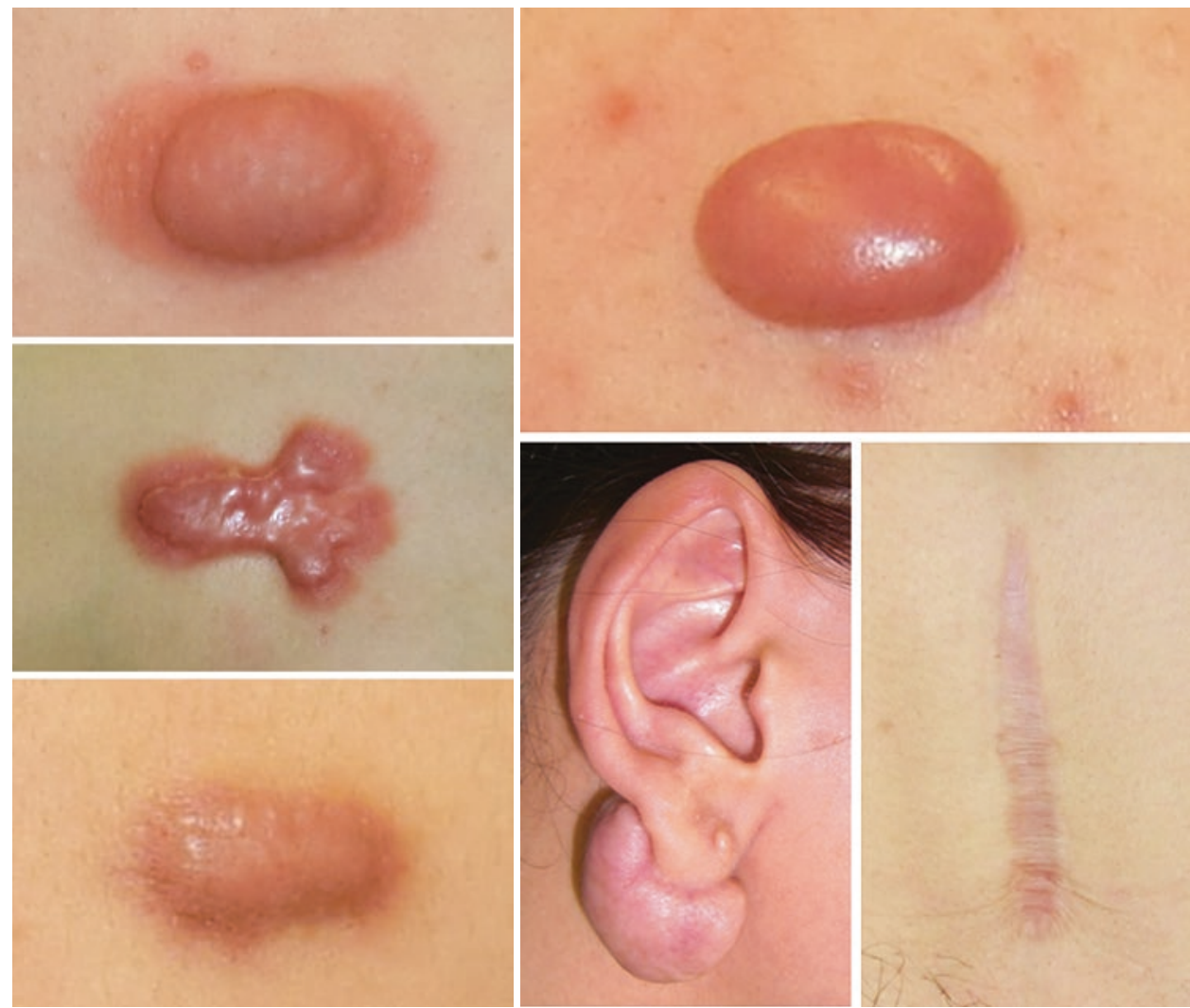

Clearly present

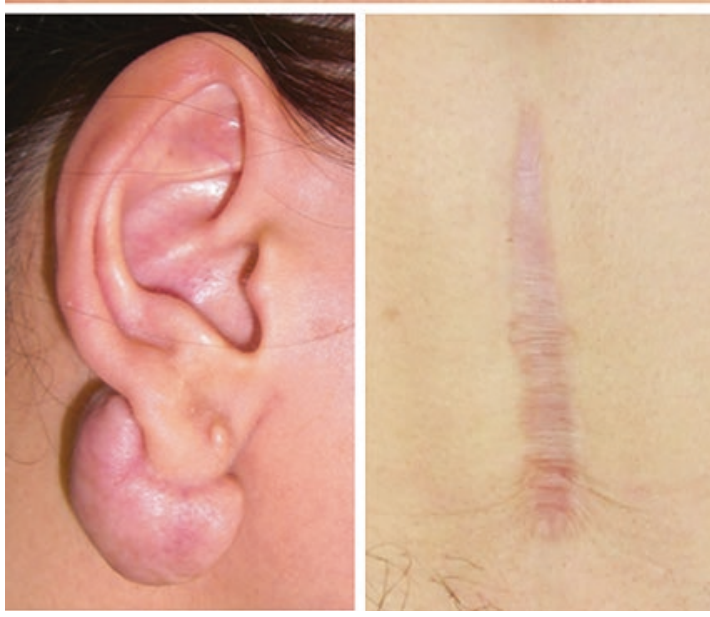

Not present

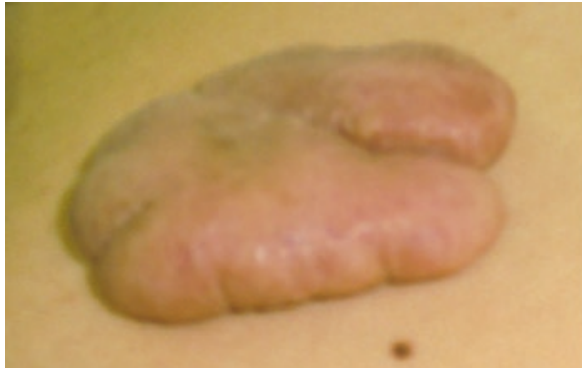

Strong

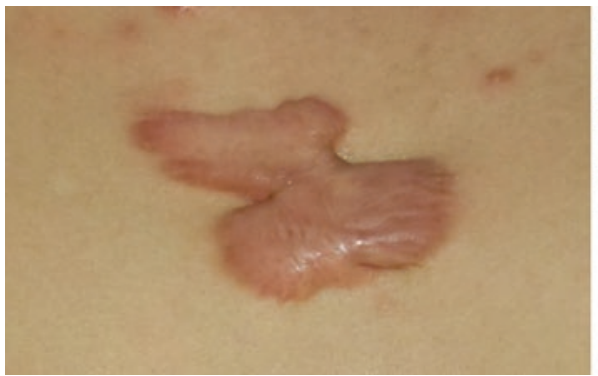

Mild
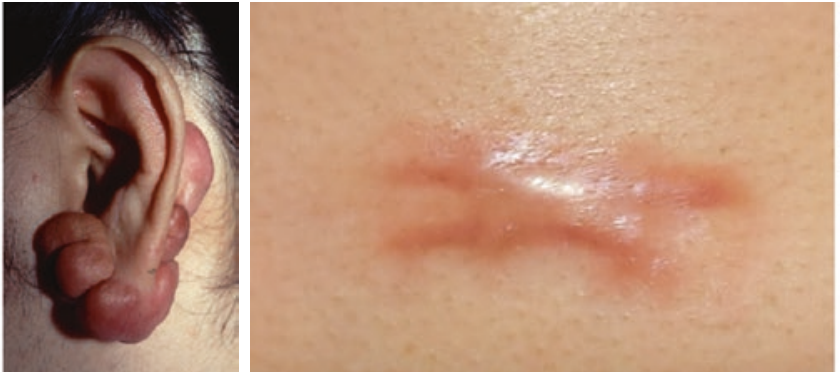

Weak
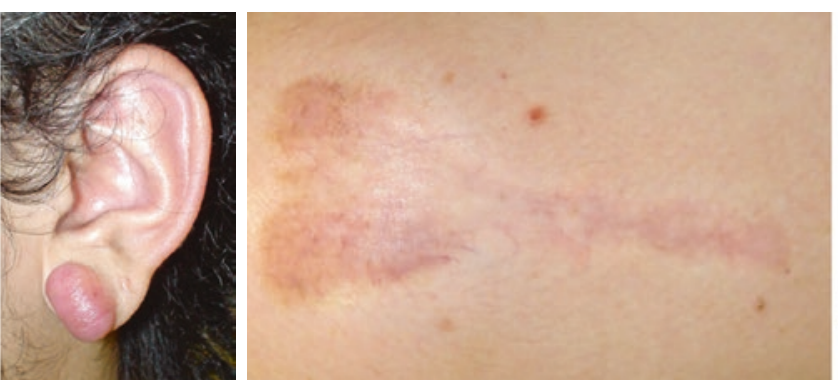

None
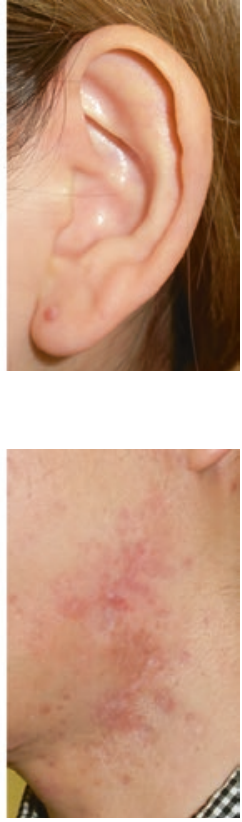

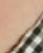

- Fig.15.5 Elevation 


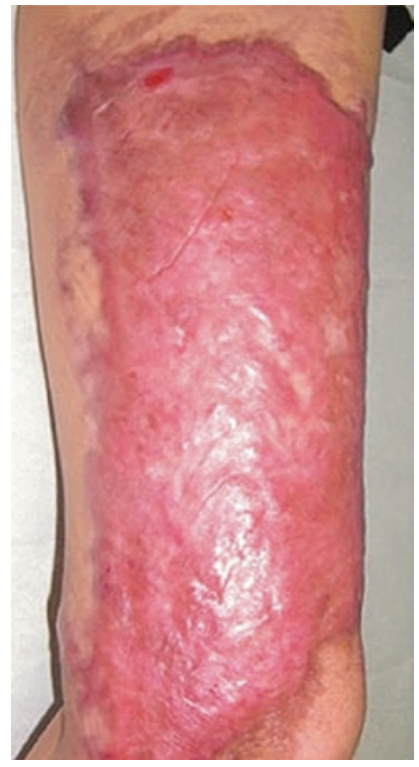

Strong

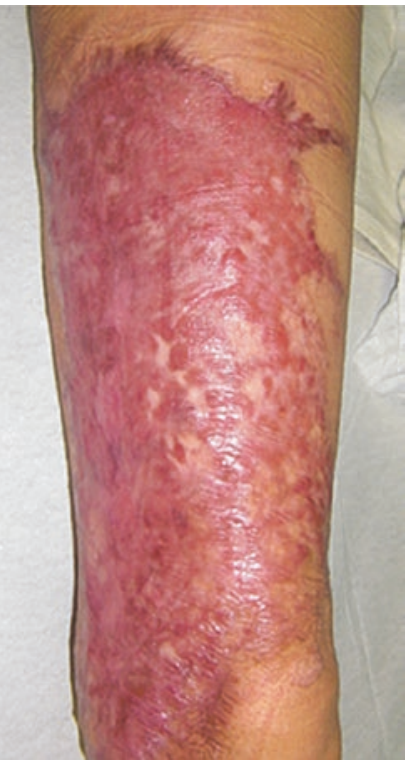

Mild

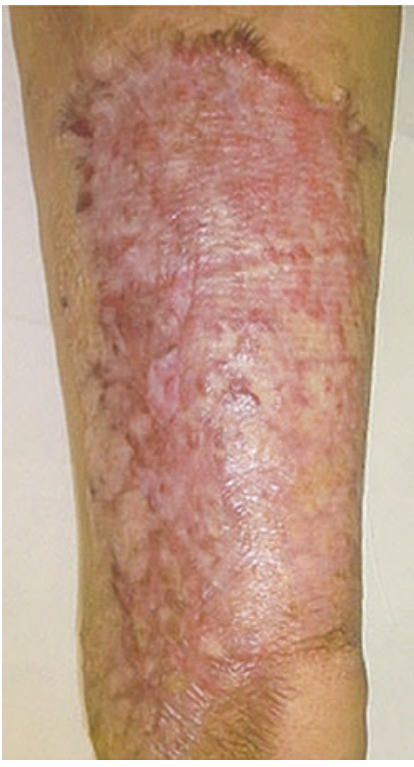

Weak

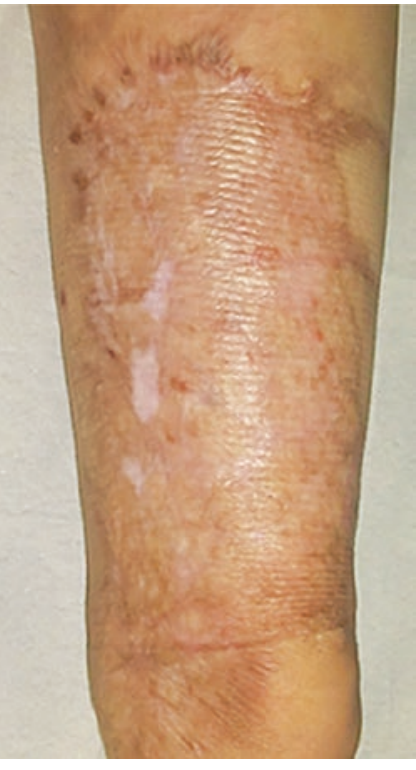

None

- Fig. 15.6 Redness of scars

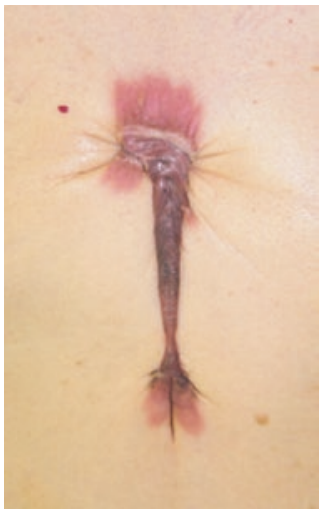

Strong
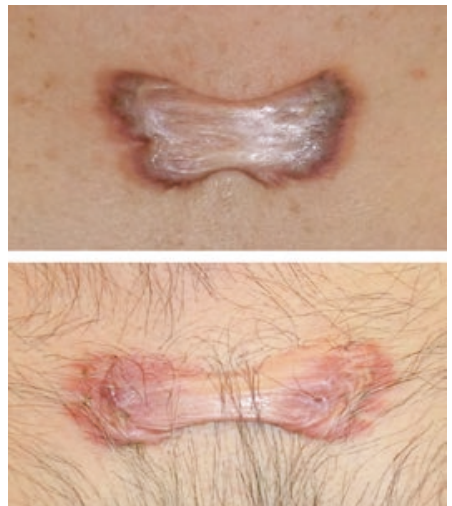

Mild
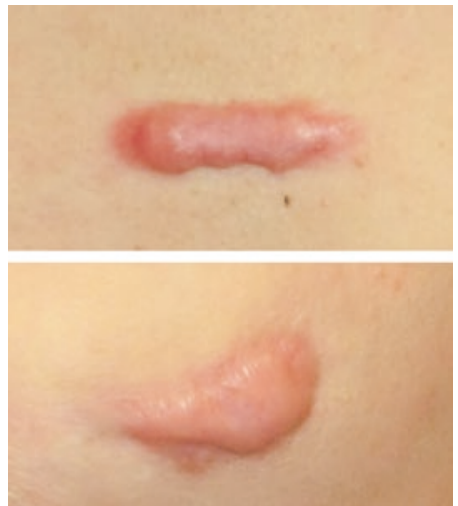

Weak

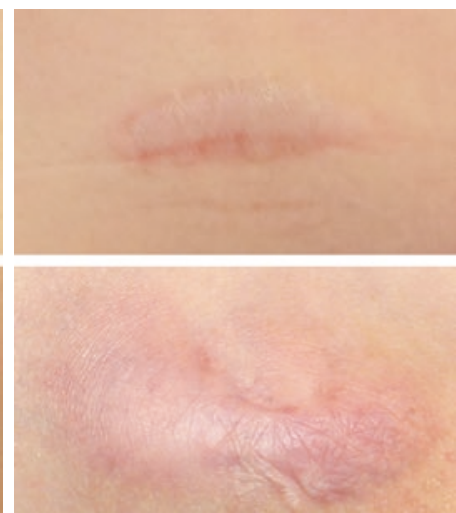

None

- Fig. 15.7 Erythema around scars 


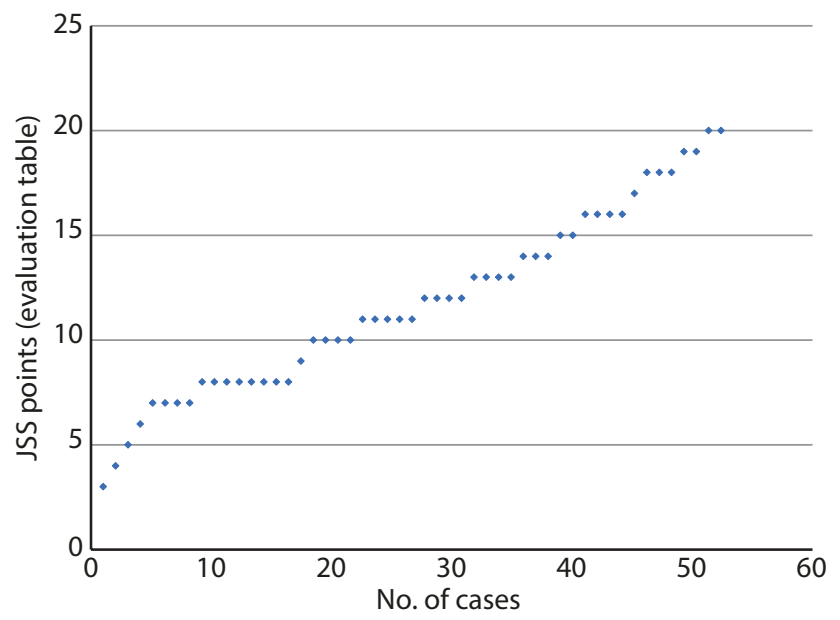

- Fig. 15.8 Clinical suitability of the classification table of JSS2015 in consecutive scar patients. We evaluated the clinical suitability of the classification table of JSS2015 by applying it to 50 consecutive scar patients in our clinic. The scores of the patients were evenly distributed between 0 and 25 points. This reflects our general clinical experience

\section{Take-Home Messages}

- The Vancouver scar scale, the Manchester scar scale, and the Patient and Observer Scar Assessment Scale (POSAS) were mainly developed to evaluate burn scars.

- The Japan Scar Workshop (JSW) developed the JSW scar scale (JSS) to evaluate keloids and hypertrophic scars.

- The JSS consists of two tables; one is a scar classification table that is used to determine whether the scar is a normal mature scar, a hypertrophic scar, or a keloid, and the other table is an evaluation table that is used to judge the response to treatment and for follow-up.

- The JSS contains sample images of each subjective keloid/hypertrophic scar item that allow the user to evaluate each item without hesitation.

\section{References}

1. Baryza MJ, Baryza GA. The Vancouver Scar Scale: an administration tool and its interrater reliability. J Burn Care Rehabil 1995;16:535-8.

2. Beausang E, Floyd H, Dunn KW, Orton CI, Ferguson MW. A new quantitative scale for clinical scar assessment. Plast Reconstr Surg. 1998;102(6):1954-61.

3. van de Kar AL, Corion LU, Smeulders MJ, et al. Reliable and feasible evaluation of linear scars by the Patient and Observer Scar Assessment Scale. Plast Reconstr Surg. 2005;116:514-22.

4. Ogawa R, Akaishi S, Akita S, Tosa Y, Yamawaki S, Okabe K, Nagao M, Yamamoto J. JSW Scar Scale Working Group. Japan Scar Workshop (JSW) Scar Scale. Available online at: http:// www.scar-keloid.com/en/index.html.

5. Ogawa R, Akaishi S, Akita S, Okabe K, Shimizu T, Sunaga A, Tosa Y, Nagao M, Yamawaki S. JSW Scar Scale Working Group. Japan Scar Workshop (JSW) Scar Scale 2015. Available online at: http://www.scar-keloid.com/en/index.html.

6. Ogawa R, Akita S, Akaishi S, et al. Diagnosis and Treatment of Keloids and Hypertrophic Scars-Japan Scar Workshop Consensus Document 2018. Burns Trauma. 2019;7:39.

7. Ogawa R, Akaishi S. Endothelial dysfunction may play a key role in keloid and hypertrophic scar pathogenesis - keloids and hypertrophic scars may be vascular disorders. Med Hypotheses. 2016;96:51-60.

8. Ogawa R, Watanabe A, Than Naing B, Sasaki M, Fujita A, Akaishi S, Hyakusoku H, Shimada T. Associations between keloid severity and single-nucleotide polymorphisms: importance of rs 8032158 as a biomarker of keloid severity. J Invest Dermatol. 2014;134(7):2041-3.

9. Koike S, Akaishi S, Nagashima Y, Dohi T, Hyakusoku H, Ogawa R. Nd:YAG laser treatment for keloids and hypertrophic scars: an analysis of 102 cases. Plast Reconstr Surg Glob Open. 2015;2(12):e272.

10. Hsueh WT, Hung KS, Chen YC, Huang YT, Hsu CK, Ogawa R, Hsueh YY. Adjuvant radiotherapy after keloid excision: preliminary experience in Taiwan. Ann Plast Surg. 2019;82(1S Suppl 1):S39-44

Open Access This chapter is licensed under the terms of the Creative Commons Attribution 4.0 International License (http://creativecommons. org/licenses/by/4.0/), which permits use, sharing, adaptation, distribution and reproduction in any medium or format, as long as you give appropriate credit to the original author(s) and the source, provide a link to the Creative Commons license and indicate if changes were made.

The images or other third party material in this chapter are included in the chapter's Creative Commons license, unless indicated otherwise in a credit line to the material. If material is not included in the chapter's Creative Commons license and your intended use is not permitted by statutory regulation or exceeds the permitted use, you will need to obtain permission directly from the copyright holder.

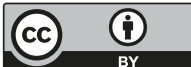

